\title{
Effects of undernutrition on survival of human immunodeficiency virus positive children on antiretroviral therapy
}

\author{
Animut Alebel ${ }^{1 *}$, Fasil Wagnew ${ }^{1}$, Cheru Tesema ${ }^{1}$, Getiye Dejenu Kibret ${ }^{1}$, Pammla Petrucka ${ }^{3,4}$ and Setegn Eshite ${ }^{2}$
}

\begin{abstract}
Background: The relationship between undernutrition and HIV is bidirectional, ultimately contributing to quality of life and survival of affected individuals. Ethiopia is a sub-Saharan nation influenced by both undernutrition and HIV. In Ethiopia, although individuals are often dually impacted, the effect of undernutrition on the survival of HIV positive children on anti-retroviral therapy (ART) has not been well investigated. Therefore, this study assessed the effect of undernutrition on survival rates of HIV positive children on ART in Amhara Regional State of Ethiopia.

Methods: An institution-based retrospective cohort study was conducted among 390 HIV positive children on ART from the 1st of January, 2012 to the 28th of February, 2017 in Amhara Regional State Referral Hospitals. A simple random sampling technique was used to select the study participants. Data were extracted by reviewing patients' ART intake and follow-up forms. Data were entered into Epi-Data Version 3.1, and analysis was done using STATA Version 13. The Kaplan-Meier survival curve was used to estimate the cumulative survival time of the sample. Log rank tests were employed to compare the survival time between different categories of explanatory variables. Bivariable and multivariable Cox proportional hazards models were fitted to identify predictors of mortality.
\end{abstract}

Results: Among the 390 records included in the final analysis, $9.7 \%$ of the individuals died within the follow-up period. In this study, the overall mortality rate was found to be 4.4 per 100 child-years ( $95 \%$ Cl: $3.2,6.0$ ) while undernourished children had a lower survival time than well-nourished children. Low hemoglobin level (AHR: 3.2, 95\% Cl: 1.4, 7.4), CD4 cell count or percent below the threshold (AHR: 5.2, 95\% Cl: 1.9, 14.1), severe stunting (AHR: 3. 9, 95\% Cl: 1.7, 9.4), severe wasting (AHR: 3.0, 95\% Cl: 1.3, 6.9) and advanced disease stage (III and IV) (AHR: $2.6,95 \%$ Cl: 1.1, 6.6) were found to be predictors of mortality.

Conclusion: There was a high rate of mortality. A significant difference was observed in the survival rate of undernourished and well-nourished children. Low hemoglobin level, CD4 count or percent below the threshold, severe wasting, severe stunting, and advanced disease stage were found to be predictors of mortality.

Keywords: Anti-retroviral therapy (ART), Children, HIV, Mortality, Undernutrition

\section{Background}

The pandemic of Human Immunodeficiency Virus (HIV) creates an enormous challenge to the survival of humankind [1]. HIV develops very rapidly among infants and children, unless early initiation of ART, almost 33\% of infants living with HIV die before their first birthday, and almost $50 \%$ die before the age of two years [2]. Comparable findings were also reported from Ethiopia,

\footnotetext{
*Correspondence: animut.a23@gmail.com; animate.a23@gmail.com ${ }^{1}$ College of Health Sciences, Debre Markos University, Debre Markos, Ethiopia Full list of author information is available at the end of the article
}

which supports this evidence [1,3]. By the end of 2016, an estimated 2.1 million children under the age of 15 were living with HIV, of which approximately $64 \%$ are from sub-Saharan Africa [4]. Ethiopia is one of the subSaharan countries with the highest prevalence of HIV. The country has approximately 57,132 , children (0-14 years) living with HIV and 1276 new infections are anticipated in 2017 [5].

Malnutrition refers to both undernutrition and overnutrition [6]; however, according to World Food Program definition, malnutrition refers to undernutrition unless 
otherwise specified [7]. Undernutrition is a major public health problem in countries with high prevalence of HIV. Independent of HIV, sub-Saharan Africa is the region of the world most seriously affected by malnutrition, reporting $21 \%$ of children under-five-year as underweight, 39\% as stunted, and $9 \%$ as wasted [8]. Ethiopia is one of the sub-Saharan African nations largely affected by malnutrition and HIV. Malnutrition is attributed as the underlying cause in $57 \%$ of child mortality in Ethiopia. Despite significant progress in the reduction of child malnutrition, it remains widespread and a serious public health problem of Ethiopian children. As indicated by the 2016 Ethiopian Demographic and Health Survey report, 38\%, 24\% and $10 \%$ of under-five children were stunted, underweight and wasted respectively [9].

The relationship between malnutrition and HIV is bidirectional. Malnutrition may increase the progression of HIV infection to Acquired Immunodeficiency Syndrome (AIDS) stage by weakening the immune functions of the body. The interplay between HIV and malnutrition is cumulative with each negatively affecting the immune system [10-12] amongst people living with HIV/AIDS, resulting in malnutrition increasing the risk of morbidity and mortality, and potentially reducing the efficacy of anti-retroviral therapy (ART) [13]. Individuals, who were malnourished at initiation of ART, experience lower survival rates compared to wellnourished counterparts [14, 15]. Study findings indicated that even a relatively small departure in weight (5\%) is associated with decreased survival rate [15].

Despite, the remarkable effects of Highly Active Antiretroviral Therapy (HAART) in the reduction of morbidity and mortality rate [1], all ART users may not equally responded to the therapy. In response to ART, there may be individual variability with some individuals having a lower progression in the recovery rate of immune function and remains at higher risk of dying from opportunistic infections. Therefore, it is better to consider another factor like nutritional status, which affecting immune response beside to ART provision [16].

In Ethiopia, different studies have been conducted to determine the predictors of mortality among HIV positive children on ART [1, 3, 17-19]. These studies showed that low hemoglobin counts, low CD4 counts below the threshold level, severe immune deficiency, age of the child at initiation of ART, adherence to ART, and severe wasting were the most common independent predictors of mortality [1, 3, 17-19]. The evidence suggests that malnutrition has a significant impact on survival of HIV positive children on ART [17, 18], although most of the studies conducted in Ethiopia did not consider baseline nutritional status as an independent predictor. In this study, nutritional status was incorporated as an independent predictor to determine its effect on survival of HIV positive children after initiation of ART. No studies have been conducted in the Amhara Regional State to determine the effect of undernutrition on survival of HIV positive children on ART. Therefore, this study will potentially inform program planners and decision makers at various stages of the HIV/AIDS care and support program. Furthermore, it will serve as a baseline data for further research.

\section{Methods}

\section{Study area, design and period}

An institution-based retrospective cohort study was conducted for the period from the 1st of January, 2012 to the 28th of February, 2017 in Amhara Regional State Referral Hospitals (i.e., Debre Markos Referral Hospital, Felege Hiwot Comprehensive Specialized Hospital, and University of Gondar Comprehensive Specialized Hospital). These three hospitals serve more than 15 million people and care for the largest proportion of HIV clients in the Region. In addition to other services, all three referral hospitals provide chronic HIV care (ART) services. Currently, 1071 children receive ART follow up in these hospitals.

\section{Population}

The source population were all HIV infected children (age $<15$ years) whoa recorded initiation on ART in Amhara Regional State Referral Hospitals. The study population were all HIV-infected children who had ART follow up and recorded from the 1st of January, 2012 to the 28th of February, 2017 in any of the three selected hospitals, and whose chart was available during the data collection period. Study participants were taken proportionally from each of the three hospitals based on the total number of children in the ART unit of these hospitals. Children, who received ART for at least for one month between the 1st of January, 2012 to February 28, 2017, were included. However, children with incomplete baseline information were excluded from the study.

\section{Sample size determination and sampling technique}

To calculate the required sample size, severe wasting, severe underweight, and severe stunting were considered as exposure variables. Moreover, severe underweight was considered as an independent variable since it yielded a maximum sample size. The sample size was determined by using a double population proportion formula, and calculated using Open Epi Version 3.To calculate our sample size, the following statistical assumptions were considered:P1:percent of exposed (severe underweight) with outcome (12.82\%);P2:percent among the nonexposed with outcome (4\%) estimated from a previous study conducted in Wolaita Health Facility, Southern Nations, Nationalities, and Peoples Region, Ethiopia [18]; $\mathbf{Z} \boldsymbol{\alpha} / 2$ :reflects CI 95\%; Z $\boldsymbol{\beta}: 80 \%$ power; and ratio of non-exposed to exposed 1:1. The final sample size was 
177 for each group and the total sample size was 354 . Finally, after adding $10 \%$ for contingency, the final sample size of our study was calculated as 390 . The sample was proportionally allocated across each participating hospital, respecting medical records of children based on the previously stated criteria. From the isolated cards in each hospital, simple random sampling technique, computer-generating method was employed to select the study participants. The selected medical charts were followed for five years or until the termination of care.

\section{Data collection tool and procedure}

The data abstraction tool was developed from a standardized ART entry and follow-up form currently used by the ART clinics. To ensure data quality, one-day training was given on the data abstraction tool and data collection process for both data collectors and supervisors. Necessary data were extracted by reviewing patients' ART cards. The most recent laboratory test results prior to ART initiation were used as a baseline value. Both principal investigators and supervisors closely supervised the entire data collection process. All collected data were examined for completeness and consistency during the data management, storage, and analysis.

\section{Data processing and analysis}

Data were entered into Epi-Data Version 3.1and analysis was done using STATA Version 13 statistical software. The WHO AnthroPlus Version 1.04 and ENA for Smart Software were used to generate the $\mathrm{Z}$ score (WAZ, HAZ and WHZ/BAZ) to define nutritional status. The assumption of Cox-proportional hazard regression model was checked using Schoenfeld residual test and variables having $P$-values $>0.1$ were considered as fulfilling the assumption criteria. Finally, the outcome of each participant was dichotomized into censored or death. The Kaplan-Meier survival curve was used to estimate survival time after initiation of ART, and log rank tests were used to compare the survival curves. The Bivariate Cox-proportional hazards regression model was fitted for each explanatory variable. Moreover, those variables having $p$-value $\leq 0.25$ in bivariable analysis were fit into the multivariable Cox-proportional hazards regression model. Hazard ratios with $95 \%$ confidence interval and $p$-values were used to measure the strength of association and to identify statistically significant predictors. In multivariable analysis, variables having $P$-values $<0.05$ were considered as statistically significant predictors of mortality.

\section{Operational definitions}

Undernutrition was defined as the child having either of $\mathrm{H} /$ Age Z-score $<-2$, or W/Age Z-score $<-2$ or W/H Z-score $<-2$ SD [20, 21].
Moderate underweight was defined as children having W/Age Z-score <- 2 SD [20, 21].

Severe underweight was defined as children having W/Age Z-score <- 3 SD [20, 21].

Moderate stunting was defined as children having $\mathrm{H} /$ Age Z-score <- 2 SD [20, 21].

Severe stunting was defined as children having H/Age Z-score $<-3$ SD [20, 21].

Moderate wasting was defined as children having W/ H Z-score <- 2 SD [20, 21].

Severe wasting was defined as children having $\mathrm{W} / \mathrm{H}$ Z-score <- 3 SD [20, 21].

Censored Individuals on ART but still alive at the end of the study or lost to follow up or individuals transfer out to other health institutions were considered as censored.

Event was defined as death of an infant or child after initiation of ART.

\section{Ethical considerations}

Ethical clearance was obtained from an institutional review committee of the School of Nursing, College of Medicine and Health Sciences, University of Gondar. The ethics committee formally waived the need for formal written consent since the study was done through retrospective reviews of patient cards (charts). Permission letters were obtained from each hospital administration of the three participating entities. Since the study was a review of medical records, individual patients were minimally at risk for harm as confidentiality was likely to be achievable. To maintain 'confidentiality, collected data were coded and locked in a separate room. After entry into the computer, all data were locked by password; as well, names and unique ART numbers were not included in the data collection forms.

\section{Results}

\section{Socio-demographic characteristics}

Among the 390 records included in the final analysis about half (53.9\%) were females, and the majority (85.4\%) were from urban areas. The mean age of the cohort at the time of ART initiation was 6.9 years ( $\mathrm{SD} \pm 0.2$ years). The mean age of the caregiver of the children was 32.9 years $(\mathrm{SD} \pm 0.4$ year) $($ Table 1$)$.

\section{Clinical characteristics of study participants}

Clinically more than half $(58.8 \%)$ of the children started ART when classified as 'mild' according to the WHO HIV clinical disease stage (I\&II). About three quarters (75.8\%) of the children had achieved appropriate developmental milestones prior to ART initiation. Prior to ART initiation, $53.3 \%$ of the children had opportunistic infections. More than two thirds (70.0\%) of the children had CD4 counts below the threshold for severe immunodeficiency. About $30.3 \%$ of the children had a 
Table 1 Baseline socio-demographic characteristics of HIV infected children on ART in Amhara Regional State referral hospitals, Ethiopia, January 1st, 2012 - February 28th, 2017

\begin{tabular}{|c|c|c|}
\hline Variables & Frequency (N) & Percentage (\%) \\
\hline \multicolumn{3}{|l|}{ Sex } \\
\hline Male & 180 & 46.1 \\
\hline Female & 210 & 53.9 \\
\hline \multicolumn{3}{|l|}{ Age } \\
\hline$<1$ year & 11 & 2.8 \\
\hline $1-5$ years & 116 & 29.7 \\
\hline $5-15$ years & 263 & 67.4 \\
\hline \multicolumn{3}{|l|}{ Residence } \\
\hline Urban & 333 & 85.4 \\
\hline Rural & 57 & 14.6 \\
\hline \multicolumn{3}{|c|}{ Marital status of caregiver (379) } \\
\hline Single & 44 & 11.6 \\
\hline Married & 191 & 50.4 \\
\hline Divorced & 54 & $14 . .3$ \\
\hline Widowed & 90 & 23.7 \\
\hline \multicolumn{3}{|l|}{ Parental status } \\
\hline Both alive & 223 & 57.2 \\
\hline Father dead & 73 & 18.7 \\
\hline Mother dead & 37 & 9.5 \\
\hline Both dead & 57 & 14.6 \\
\hline \multicolumn{3}{|c|}{ Caregiver of the child } \\
\hline Parent & 324 & 83.0 \\
\hline Sister/Brother & 17 & 4.4 \\
\hline Uncle/aunt & 9 & 2.3 \\
\hline Grandparent & 25 & 6.4 \\
\hline Others & 15 & 3.9 \\
\hline
\end{tabular}

history of regimen change throughout the entire follow up. From those who had a history of regimen change, toxicity or drug side effect $(44.8 \%)$ was the most common reason followed by drug out of stock (24.6\%) and clinical failure $(9.8 \%)$. In addition, among those experiencing drug side effects $(17.8 \%)$ during the follow-up period, anemia (30.8\%) was the most common complaint followed by nausea (20.8\%) and rash (12.3\%) (Table 2).

\section{Nutritional status of the study participants}

At baseline, about one-fifth (20.3\%) of the study participants were moderately underweight, $12.0 \%$ were moderately stunted, and $12.6 \%$ were moderately wasted. In addition, the proportions of presenting child malnutrition cases were classified as severe stunting (19.7\%), severe wasting (13.9\%), and severe underweight (15.1\%) (Table 3).

\section{Incidence of mortality}

Within a median follow-up period of 24.65 months with IQR (12- 39 months), $9.7 \%$ of the study participants died, $5.4 \%$ were lost to follow up, $14.4 \%$ were transferred out, leaving the remaining $70.5 \%$ alive. The overall mortality rate of the entire follow-up was 4.4 per 100 child years (95\% CI: 3.2, 6.0). Regarding the time of death, $50 \%, 63 \%$, and $68 \%$ of the deaths occurred within the first six, twelve, and eighteen months of ART initiation, respectively. The mean survival time of the entire follow-up was 56.4 months (95\% CI: 53.7, 57.5). The cumulative probabilities of survival at $3,6,12$, 24, and 60 months after initiation of ART were 0.966, $0.950,0.935,0.831$, and 0.831 , respectively. The cohort contributed a total of 10,376 child-months of follow-up.

\section{Survival function of different predictor variables}

To test the equality of survival curves for different categorical predictor variables the Cochran-Mantel Haenszel log rank test was used. The results showed that there was a significant difference in the survival function of different categorical variables; specifically, nutritional status (under or normal), hemoglobin $(<10 \mathrm{~g} / \mathrm{dl}$ and $\geq 10 \mathrm{~g} / \mathrm{dl}$ ), CD4 count or percent (below and above the threshold), and WHO HIV clinical disease staging (i.e., mild to advanced).The mean survival time for children who were undernourished at the time of ART initiation was 50.6 months (SD \pm 1.7 ), but 61.1 months (SD \pm 0.6$)$ for those who were well nourished. This difference was statistically significant with a $P$-value $<0.001$ (Fig. 1).

In this study, children who had low hemoglobin levels $(<10 \mathrm{~g} / \mathrm{dl})$ had a lower survival time as compared to those with high hemoglobin level $(\geq 10 \mathrm{~g} / \mathrm{dl})$. The mean survival time of children having low hemoglobin level was 39.6 months $(\mathrm{SD} \pm 4.1)$ and the mean survival time of children having hemoglobin level $\geq 10 \mathrm{~g} / \mathrm{dl}$ was 57.5 months $(\mathrm{SD} \pm 0.9)$. This difference was statically significant with $P$-value $<0.001$ (Fig. 2).

The mean survival time for children classified as WHOHIV clinical stages I or II at the time of ART initiation was 59.5 months $(\mathrm{SD} \pm 0.9)$ as compared to those assessed as WHO HIV clinical stages III and IV with a mean survival time of 50.3 months $(S D \pm 1.9)$. This difference is statistically significant with $P$-value $<0.001$ (Fig. 3).

The mean survival time for initiates withCD4 count or percent below the threshold was 53.9 months ( $\mathrm{SD} \pm 1.3$ ), which was lower than the mean survival time of individuals who had CD4 count or percent above the threshold with a mean survival time of 59.3 months (SD \pm 1 . 2). This difference was statistically significant with P-value $=0.011$ (Fig. 4). 
Table 2 Baseline clinical and immunological profile of HIV positive children on ART in Amhara Regional State referral hospitals, Ethiopia from the 1st of January, 2012 - the 28th February, 2017

\begin{tabular}{lll}
\hline Variables & Frequency $(\mathrm{N})$ & Percentage (\%) \\
\hline Ol at baseline & & \\
Yes & 182 & 53.3 \\
No & 208 & 46.7
\end{tabular}

Functional status (age $\geq 5$ year) $(N=262)$

Working
Ambulatory
Bedridden

Developmental History (age $<5$ years) $(N=128)$

Appropriate
Delayed
Regressive

WHO clinical stage

Stage I and II
Stage III and IV
Past TB test before ART

Past TB test before ART

$\begin{array}{lll}\text { Not determined } & 310 & 79.5 \\ \text { Negative } & 37 & 9.5 \\ \text { Positive } & 43 & 11.0\end{array}$

Past TB treatment

$\begin{array}{lll}\text { No treatment } & 346 & 88.7 \\ \text { 2SRHZ/4RH } & 30 & 7.7 \\ \text { 2HRZES/4HRE } & 3 & 0.8 \\ \text { HRZE/4RH } & 11 & 2.8\end{array}$

CD4 count or percent

Below the threshold

Above the threshold

Hemoglobin level

$$
<10 \mathrm{~g} / \mathrm{dl}
$$

$$
\geq 10 \mathrm{~g} / \mathrm{dl}
$$

ART eligibility criteria

Immunologic/ CD4

WHO clinical stage

Both clinical and immunologic

Without criteria

Type of Regimen during follow up

$$
\begin{aligned}
& 4 \mathrm{a}=\mathrm{d} 4 \mathrm{t}-3 \mathrm{TC}-\mathrm{NVP} \\
& 4 \mathrm{~b}=\mathrm{d} 4 \mathrm{t}-3 \mathrm{TC}-\mathrm{EFV} \\
& 4 \mathrm{c}=\text { AZT-3TC-NVP } \\
& 4 \mathrm{~d}=\text { AZT-3TC-EFV } \\
& 1 \mathrm{e}=\text { TDF-3TC-EFV } \\
& 1 \mathrm{~h}=\text { ABC-3TC-NVP } \\
& 1 \mathrm{~g}=\text { ABC-3TC-EFV }
\end{aligned}
$$

48
22
149
78
35
10
13

Table 2 Baseline clinical and immunological profile of HIV positive children on ART in Amhara Regional State referral hospitals, Ethiopia from the 1st of January, 2012 - the 28th February, 2017 (Continued)

\begin{tabular}{lll}
\hline Variables & Frequency $(\mathrm{N})$ & Percentage (\%) \\
\hline 2nd line & 9 & 2.3 \\
Others & 26 & 6.7 \\
Ol during follow-up & & \\
Yes & 107 & 27.4 \\
No & 283 & 72.6 \\
Cotrimoxazole preventive therapy & & \\
Yes & 233 & 59.7 \\
No & 157 & 40.3 \\
Regimen change during follow-up & & \\
Yes & 118 & 30.3 \\
No & 272 & 69.7 \\
Regimen stopped during follow-up & & \\
Yes & 18 & 4.6 \\
No & 372 & 95.4 \\
ART adherence in the 1st 3 months & & 92.2 \\
Good /fair & 495 & 7.8 \\
Poor & 42 & \\
\hline
\end{tabular}

\section{Bivariable and multivariable cox-regression analysis}

In the bivariable analysis, being male, aged 5-15 years, living in rural areas, hemoglobin level $<10 \mathrm{~g} / \mathrm{dl}$, presence of OI, CD4 cell count or percentage below the threshold, categorized as WHO HIV clinical stages III\&IV, underweight (moderate and severe), stunted (moderate and severe) and wasted (moderate and severe) were found to be significant predictors of mortality. In the multivariable Cox-regression analysis, only five variables were found to be predictors of mortality. The result of

Table 3 Baseline nutritional status of HIV positive children on ART in Amhara Regional State referral hospitals, Ethiopia from the 1st of January, 2012 - the 28th February, 2017

\begin{tabular}{lll}
\hline Variables & Frequency $(\mathrm{N})$ & Percent $(\%)$ \\
\hline Underweight & 252 & 64.6 \\
$\quad$ Normal & 79 & 20.3 \\
$\quad$ Moderate $(\mathrm{WAZ}<-2)$ & 59 & 15.1 \\
$\quad$ Severe $(\mathrm{WAZ}<-3)$ & & \\
Stunting & 266 & 68.2 \\
$\quad$ Normal & 47 & 12.0 \\
Moderate $(\mathrm{HAZ}<-2)$ & 77 & 19.7 \\
$\quad$ Severe $(\mathrm{HAZ}<-3)$ & & \\
Wasting & 287 & 73.6 \\
$\quad$ Normal & 49 & 12.6 \\
$\quad$ Moderate $(\mathrm{WHZ}$ or BAZ $<-2)$ & 54 & 13.9 \\
$\quad$ Severe $(\mathrm{WHZ}$ or BAZ $<-3)$ & 54 \\
\hline
\end{tabular}




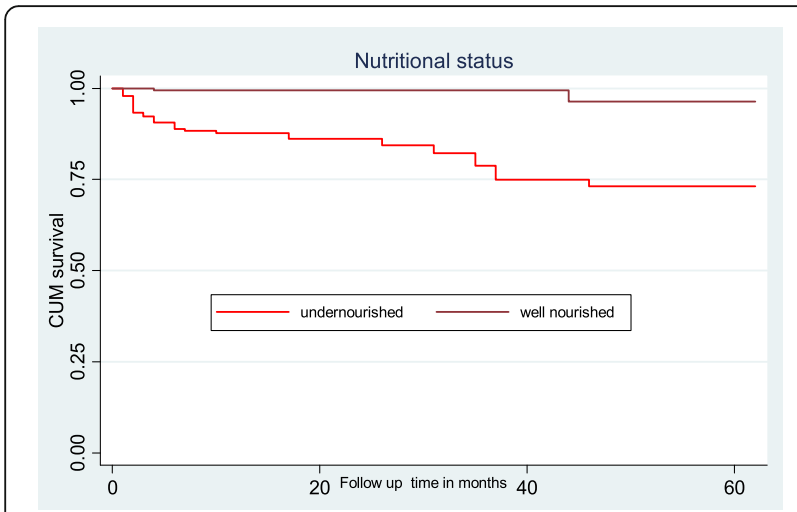

Fig. 1 The Kaplan-Meier survival curves to compare survival time of HIV positive children on ART with different categories of nutritional status in Amhara Regional State referral hospitals, Northwest Ethiopia from January 1st, 2012- February 28th, 2017

multivariable analysis revealed that children with advanced WHO HIV clinical stages (III and IV) were 2.6 times higher risk of death as compared to those with WHO HIV clinical stage (I and II) (AHR: 2.6, 95\% CI: 1.1, 6.6). In this study, CD4 count was found to be another predictor of mortality. Children exhibiting CD4 cell count or percentages below the threshold were 5.2 times at higher risk of death as compared to cohort members below thresholds (AHR: 5.2, 95\% CI: 1.9, 14.1). Moreover, initiates with hemoglobin levels less than $10 \mathrm{~g} / \mathrm{dl}$ were at 3.2 times higher risk of death than those with hemoglobin levels greater than or equal to $10 \mathrm{~g} / \mathrm{dl}$ (AHR: 3.2, 95\% CI: 1.4, 7.4). Case presence of severe stunting at the beginning of ART showed 3.9 times higher risk of death than non-stunting cases (AHR: 3.9, 95\% CI: 1.7, 9.4). Furthermore, children who were severely wasted were at 3.0 times higher risk of death as compared to those who were not wasted (AHR: 3.0, 95\% CI: 1.3, 6.9) (Table 4).

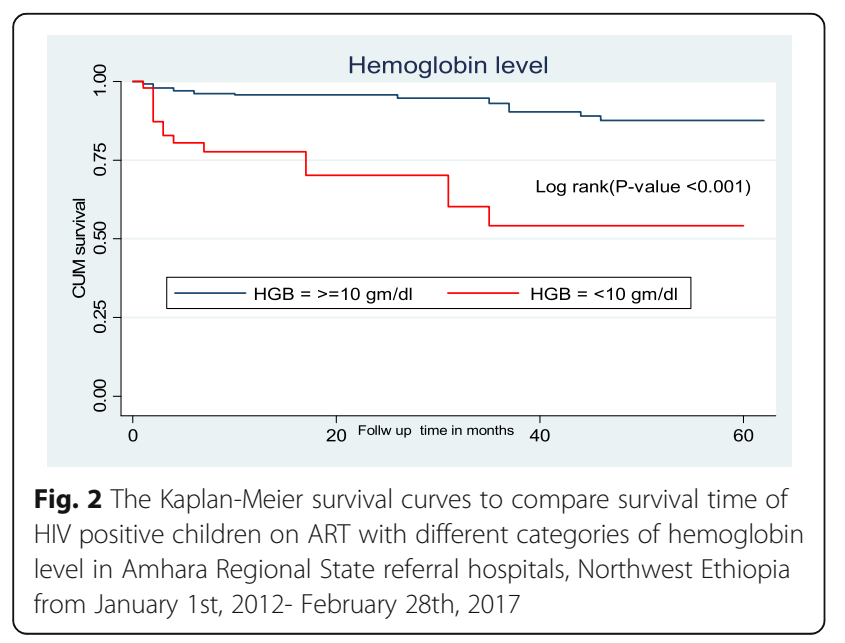

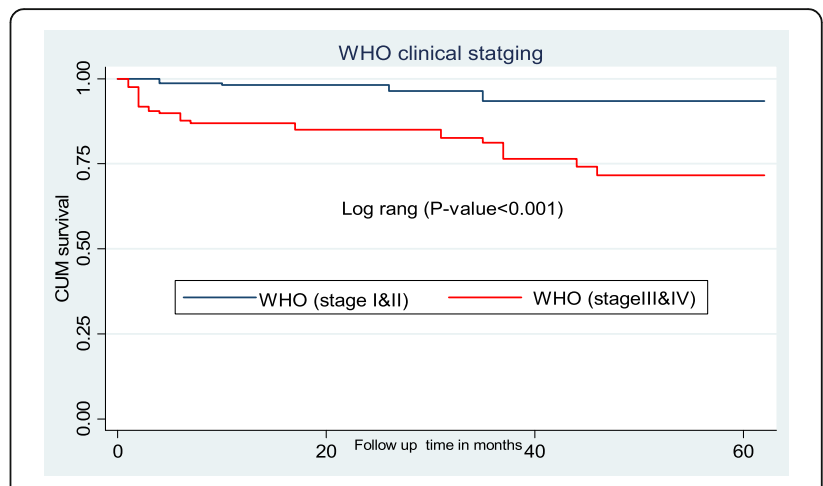

Fig. 3 The Kaplan-Meier survival curves to compare survival time of HIV positive children on ART with different categories of WHO clinical staging in Amhara Regional State referral hospitals, Northwest Ethiopia from January 1st- February 28th, 2017

\section{Discussion}

In this retrospective cohort study, the incidence and predictors of mortality were determined among HIV positive children on ART. At the end of follow-up, about 9.7\% patients were deceased and 5.4\% patients were lost to follow-up. The overall mortality rate of this study was 4.4 per 100 child-years $(95 \%$ CI: $3.2,6.0)$ which is consistent with findings in Congo (3.4 deaths per 100 child-years) [22] and at Bahir Dar Referral Hospital, Northwest Ethiopia (four deaths per 100 child-years) [1]. However, the mortality rate reported in this study is higher than studies reported from Mekelle Hospital, Northern Ethiopia (1.4 deaths per 100 child-years) [23], Zimbabwe (2.9 deaths per 100 child-years) [24], Wolaita Zone health facilities, Southern Ethiopia (2.1 deaths per 100 child-years) [18], and the Asia Pacific region (1.9 deaths per 100 child-years) [25].Conversely, the mortality rate found in this study is much lower than a Kenyan study where the findings reflected 8.4 deaths per 100 child-years [26].

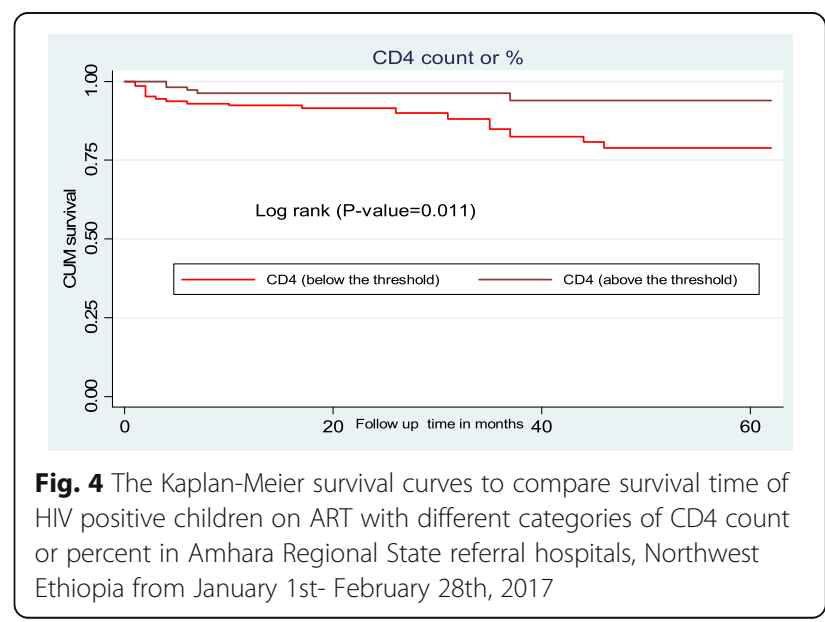


Table 4 The bivariable and multivariable Cox regression analysis of predictors of mortality among HIV positive children on ART in Amhara Regional State referral hospitals, Ethiopia from January 1st, 2012 - February 28th, 2017

\begin{tabular}{|c|c|c|c|c|}
\hline \multirow{2}{*}{$\begin{array}{l}\text { Variables } \\
\text { Sex }\end{array}$} & \multicolumn{2}{|c|}{$\begin{array}{l}\text { Survival status } \\
\text { Dead Censored }\end{array}$} & \multirow[t]{2}{*}{ CHR $(95 \% \mathrm{Cl})$} & \multirow[t]{2}{*}{ AHR (95\%Cl) } \\
\hline & & & & \\
\hline Male & 23 & 154 & $2.5(1.3,5.0)$ & $1.3(0.6,3.0)$ \\
\hline Female & 15 & 198 & 1 & 1 \\
\hline \multicolumn{5}{|l|}{ Age } \\
\hline$<1$ yer & 3 & 8 & $4.9(1.4,17.0)$ & $2.5(0.6,9.9)$ \\
\hline $1-5$ years & 17 & 99 & $2.2(1.1,4.3)$ & $1.7(0.7,3.7)$ \\
\hline 5-15 years & 18 & 245 & 1 & 1 \\
\hline \multicolumn{5}{|l|}{ Residence } \\
\hline Urban & 35 & 298 & 1 & 1 \\
\hline Rural & 3 & 54 & $0.6(0.2,2.0)$ & $0.5(0.1,1.7)$ \\
\hline \multicolumn{5}{|l|}{ Ol at baseline } \\
\hline Yes & 30 & 152 & $4.3(2.0,9.0)$ & $1.9(0.8,4.5)$ \\
\hline No & 8 & 200 & 1 & 1 \\
\hline \multicolumn{5}{|l|}{ WHO clinical staging } \\
\hline Stage | and || & 8 & 221 & 1 & 1 \\
\hline Stage III and IV & 30 & 131 & $5.6(2.6,12.3)$ & $2.6(1.1,6.6)^{* *}$ \\
\hline \multicolumn{5}{|l|}{ CD4 count or percent } \\
\hline Below the threshold & 33 & 2410 & $3.2(1.2,8.2)$ & $5.2(1.9,14.1)^{* *}$ \\
\hline Above the threshold & 5 & 112 & 1 & 1 \\
\hline \multicolumn{5}{|l|}{ Hemoglobin level } \\
\hline$<10 \mathrm{~g} / \mathrm{dl}$ & 15 & 32 & $6.2(3.2,11.9)$ & $3.2(1.4,7.4)^{* *}$ \\
\hline$\geq 10 \mathrm{~g} / \mathrm{dl}$ & 23 & 320 & 1 & 1 \\
\hline \multicolumn{5}{|l|}{ Underweight } \\
\hline Normal & 10 & 242 & 1 & \\
\hline Moderate $(W A Z<-2$ & 13 & 66 & $4.2(1.8,9.6)$ & $2.4(0.9,6.4)$ \\
\hline Severely $(\mathrm{WAZ}<-3)$ & 15 & 44 & $6.8(3.01,15.2)$ & $1.3(0.5,3.6)$ \\
\hline \multicolumn{5}{|l|}{ Stunting } \\
\hline Normal & 12 & 254 & 1 & 1 \\
\hline Moderate $(H A Z<-2)$ & 8 & 39 & $3.9(1.6,9.7)$ & $2.3(0.9,6.29)$ \\
\hline Severe $(H A Z<-3)$ & 18 & 59 & $6.1(2.9,12.9)$ & $3.9(1.7,9.4)^{* *}$ \\
\hline \multicolumn{5}{|l|}{ Wasting } \\
\hline Normal & 18 & 269 & 1 & 1 \\
\hline Moderate $(\mathrm{WHZ}$ or $\mathrm{BAZ}<-2)$ & 5 & 44 & $1.5(0.5,4.0)$ & $1.2(0.4,3.6)$ \\
\hline Severe $(\mathrm{WHZ}$ or $\mathrm{BAZ}<-3)$ & 15 & 39 & $4.5(2.2,9.0)$ & $3.0(1.3,6.9)^{* *}$ \\
\hline
\end{tabular}

**Significant predictors in the multivariable analysis

Explanations for variation in the incidence of mortality rate might be due to the difference in sample size, study settings, study period, and/or characteristics of study participants. The higher mortality in the current study may relate to the fact that more than two-thirds (70.0\%) of participants had CD4 counts or percentages below the threshold for severe immunodeficiency at the time of ART initiation. Children with CD4 counts or percentages below the threshold are at higher risk of developing opportunistic infections, which escalates the possibility of death during the early phase of treatment prior to responding to HAART drugs. Another possible explanation might relate to this study being conducted in referral hospitals, which provide tertiary level services for patients from health centers or general hospitals that are often experiencing advanced disease stage and complexity of management for ART initiation. These factors individually and collectively could increase the incidence of mortality. 
The aim of this study was to determine the effect of nutritional status of undernourished children was much lower than well-nourished children (61.1 months with SD \pm 0.6 ). Supportive findings was reported from a study conducted in Singapore [27]. According to this study, malnutrition was significantly associated with reduced survival of patients taking ART. It is known that undernourished children are more prone to develop opportunistic infections than well-nourishedchildren. The presence of opportunistic infections during ART initiation increase piles burden, which results in drug-drug interactions and potentiates early death after ART initiation either due to drug side effect or due to opportunistic infections.

Concerning the interval from ART initiation to death, $63 \%$ of the deaths occurred within the first 12 months. In this study, early mortality (death $\leq 12$ months of ART initiation) was higher than late mortality (death $\geq$ 12 months after ART initiation) with an incidence rate of 7.2 per 100 child-years and 2.4 per 100 child-years respectively. This finding is consistent with a study conducted in Mekelle Hospital, Northern Ethiopia, which showed that early mortality (death $<18$ months after ART initiation) was higher than late mortality (death $\geq 18$ months after ART initiation [23]. This finding is also in line with other studies conducted in other subSaharan Africa countries which showed that most of the deaths occurred in the first 6 months following ART initiation $[28,29]$.This high early mortality after ART initiation in our study area might be attributed to the proportion (70\%) of the patients having CD4 counts or percentages below the threshold for severe immunodeficiency at the time of ART initiation. Patients with severe immunodeficiency are greatly affected by various types of opportunistic infections and which could compromise proper treatment outcomes and may accounts for our findings.

The present study explored predictors of mortality among study participants. In this study, low hemoglobin level was found to be a predictor of mortality among children living with HIV on ART. Children who had low hemoglobin levels at the time of ART initiation have a higher risk of death as compared to those who had hemoglobin levels $\geq 10 \mathrm{~g} / \mathrm{dl}$. Previous studies from Ethiopia reported that low hemoglobin level was a strong predictor of mortality $[1,17,23,30]$, and studies from other subSaharan African countries also demonstrated that low hemoglobin was a predictor of mortality $[26,29,31]$. In this study, nearly $58.2 \%$ of our study participants were taking the drug of 4c (AZT-3TC-EFV) or 4d (AZT-3TC$\mathrm{NVP}$ ) during the follow-up time. Zidovudine (AZT) is one of the most common causes of anemia (megaloblastic anemia) among patients living with HIV. Cotrimoxazole preventive therapy (CPT) might be another cause of anemia among children living with HIV, in which more than half (63.2\%) of participants have been taking CPT.
Children, who had CD4 counts or percents below the threshold, yet another strong predictor of mortality, showed a higher risk of death than their counterparts. This finding is consistent with other previous studies conducted in Ethiopia [1, 17, 23], India [32], Congo [33], Tanzania [31], Bangladesh [34] and Malaysia [35]which all indicate that low CD4 count was an independent predictor of mortality. Children with severe immunodeficiency are at higher risk of developing serious and lifethreatening opportunistic infections, such as CNS toxoplasmosis and cryptococcal meningitis.

An advanced WHO HIV clinical staging (III and IV) was also an independent predictor of mortality. Children with advanced WHO HIV clinical stage (III and IV) at the time of ART initiation have a higher risk of death as compared to their counterparts with mild status (i.e., WHOHIV clinical disease stage (I and II)). Similar results were reported from previous studies conducted in Ethiopia [23, 30, 36], Kenya [26], Malawi [37] and Zimbabwe [24]which all indicated that advanced WHO HIV clinical disease stages was a predictorof mortality. For those living with HIV, as WHO HIV clinical staging becomes more advanced, the risk of developing and recurrence of opportunistic infection also simultaneously increased, which might be associated with the cause of death.

In this study, severe stunting was another predictor of mortality among HIV positive children on ART. Children who were severely stunted prior to ART initiation have a higher risk of death as compared to those who were not stunted. Reasonably, malnutrition is a common complication of HIV infection. Severe stunting is associated with a weakened immune system and complicates the treatment of diseases by affecting intestinal absorption of drugs and the ability to absorb various nutrients [31].

Furthermore, being severely wasted prior to ART initiation was a strong predictor of mortality. Those who were severely wasted prior to ART initiation have a higher risk of death as compared to those who were not wasted. Comparable reports were also noted in previous in Ethiopia [17, 18]. A study from Kenya revealed that (WHZ <-2) increased the risk of death among HIV positive children receiving HAART [26]. Similarly, a study from Tanzania reported (WHZ and BAZ of $\leq-2$ ) significantly increased the risk of mortality in the first 90 days of ART initiation [31]. Generally, many factors place HIV patients at higher risk of developing undernutrition than the general population. Factors such as reductions of food intake, poor absorption of nutrients that may be the result of recurrent or chronic diarrhea, HIV-caused intestinal cell damage, increased energy needs because of virus replication and opportunistic infections (OIs), have been previously recognized [12, 38]. 


\section{Study limitations and strengths}

This study experienced inconsistencies in ascertaining causes of death, especially for those who died at home. Loss to follow-up might also have included those died without being reported. Furthermore, important predictors of mortality, like viral load and micronutrient deficiency, were not considered. Despite the above limitations, the study was conducted over a significant period, which increases the period of observation, thereby increasing the number of events.

\section{Conclusion}

The findings of this study indicated that there was a high rate of mortality among HIV positive children on ART. In this study, nutritional status was found to have a significant effect on the survival of HIV positive children on ART. Anemia, baseline CD4 count or percent below the threshold, advanced WHO HIV clinical disease staging (III and IV), severe stunting, and severe wasting were found to be independent predictors of mortality among HIV children on ART. Therefore, studying the impacts of maximizing nutritional supplements and other nutritional interventions are needed to be encouraged with special emphasis HIV positive children.

\section{Abbreviations}

AIDS: Acquired Immune Deficiency Syndrome; HAZ: Height for Age Z score; Hgb: Hemoglobin; HIV: Human Immunodeficiency Virus; WAZ: Weight for Age Z score; WHO: World Health Organization.; WHZ: Weight for Height Z score

\section{Acknowledgments}

The authors would like to acknowledge the University of Gondar, College of Medicine and Health Sciences for financial support of this research project. The authors also extend their special thanks for both data collectors and supervisors. The authors also would like to acknowledge Mr. Nurilign Abebe (BSC,MPH, Assistant professor), Mr. Getachew Mullu (BSC, MSc)and Mr. Degefaye Zelalem (BSC,MSc) for their constructive comments and suggestions.

\section{Funding}

Not applicable

\section{Availability of data and materials}

No additional data are required; all information is clearly stated in the main manuscript.

\section{Authors' contribution}

AA: conception of the research idea, study design, data collection, analysis and interpretation, and manuscript write-up. FW, CT, PP, GDK and SE: data collection, analysis and interpretation, and manuscript write-up. All authors have read and approved the final manuscript.

\section{Ethics approval and consent to participate}

Ethical clearance was obtained from an institutional review committee of the School of Nursing, College of Medicine and Health Sciences, University of Gondar. The ethics committee formally waived the need for formal written consent since the study was done through retrospective reviews of patient cards (charts). Permission letter was obtained from each hospital administration. Since, the study was reviewed medical records; the individual patients were minimally at risk for harm as confidentiality was likely to be attainable. To maintain confidentiality, collected data were coded and locked in a separate room. After entry into the computer, all data were locked by password; as well, names and unique ART numbers were not included in the data collection format.
Consent for publication

Not applicable

\section{Competing interests}

The authors have declared that they have no competing interests.

\section{Publisher's Note}

Springer Nature remains neutral with regard to jurisdictional claims in published maps and institutional affiliations.

\section{Author details}

${ }^{1}$ College of Health Sciences, Debre Markos University, Debre Markos, Ethiopia. ${ }^{2}$ College of Medicine and Health Sciences, University of Gondar, Gondar, Ethiopia. ${ }^{3}$ College of Nursing, University of Saskatchewan, Saskatoon, Canada. ${ }^{4}$ School of Life Sciences and Bioengineering, Nelson Mandela African Institute of Science and Technology, Arusha, Tanzania.

Received: 3 November 2017 Accepted: 23 February 2018

Published online: 27 February 2018

\section{References}

1. Koye DN, Ayele TA, Zeleke BM. Predictors of mortality among children on antiretroviral therapy at a referral hospital, Northwest Ethiopia: a retrospective follow up study. BMC Pediatr. 2012;12:161.

2. UNICEF: Towards an AIDS-free generation: children and AIDS: sixth stocktaking report, 2013. 2013. Available from http://www.unaids.org/sites/default/files/ media_asset/20131129_stocktaking_report_children_aids_en_0.pdf.

3. Kedir AA, Desta A, Fesseha G. Factors affecting survival of HIV positive children taking antiretroviral therapy at Adama referral hospital and medical college, Ethiopia. J AIDS Clin Res. 2014;2014

4. UNIAS: UNAIDS data 2017. 2017. Available at www.unaids.org/sites/default/ files/media_asset/20170720_Data_book_2017_en.pdf.

5. The Ethiopian Public Health Institute: HIV related estimates and projections for Ethiopia-2017. 2017. Available at https:/www.ephi.gov.et/images/pictures/ download2009/HIV_estimation_and_projection_for_Ethiopia_2017.pdf.

6. World Health Organization: Nutrition for health and development protection of the human environment. 2005. Available at www.who.int/ quantifying_ehimpacts/publications/MalnutritionEBD12.pdf.

7. WFP. A manual for measuring and interpreting malnutrition and mortality. In: Romero-Corral A, editor. 2004. Available from https://es.scribd.com/ document/...3-Chapter-1-Defining-Measuring-Malnutr-Pgs-15-32.

8. WHO. W: Levels and trends in child malnutrition: UNICEF-WHO-the World Bank joint child malnutrition estimates. Washington DC; 2012.

9. Centeral Statistics: Demographic and health survey key indicators. 2016 Available at https://www.usaid.gov/sites/default/files/documents/1860/ Ethiopia\%20DHS\%202016\%20KIR\%20-\%20Final\%2010-17-2016.pdf.

10. Wasie B, Kebede Y, Yibrie A. Nutritional status of adults living with HIV/AIDS at the University of Gondar Referral Hospital, Northwest Ethiopia. Ethiopian Journal of Health and Biomedical Science. 2014;3(1)

11. Duggal S, Chugh TD, Duggal AK. HIV and malnutrition: effects on immune system. Clin Dev Immunol. 2012;2012:784740.

12. FMOH: Ministry of Health National Nutrition and HIV/AIDS implementation reference manual. In $n_{i ;}$ 2008:3. Available from https://www.fantaproject.org/ sites/default/files/resources/Ethiopia-HIV-Nutrition-Guidelines-2008.pdf.

13. Benzekri NA, Sambou J, Diaw B, el HI S, Sall F, Niang A, Ba S, Ngom Gueye $N F$, Diallo MB, Hawes SE, et al. High prevalence of severe food insecurity and malnutrition among HIV-infected adults in Senegal, West Africa. PLoS One. 2015;10(11):e0141819.

14. Johannessen A, Naman E, Ngowi BJ, Sandvik L, Matee MI, Aglen HE, Gundersen SG, Bruun JN. Predictors of mortality in HIV-infected patients starting antiretroviral therapy in a rural hospital in Tanzania. BMC Infect Dis. 2008:8:52.

15. Hu W, Jiang $H$, Chen W, He SH, Deng B, Wang WY, Wang Y, Lu CD, Klassen $\mathrm{K}$, Zeng J. Malnutrition in hospitalized people living with HIV/AIDS: evidence from a cross-sectional study from Chengdu, China. Asia Pac J Clin Nutr. 2011;20(4):544-50

16. Floridia M, Fragola V, Galluzzo C, Giannini G, Pirillo M, Andreotti M, Tomino C. Group VftIIS: HIV-related morbidity and mortality in patients starting protease inhibitors in very advanced HIV disease (CD4 count of $<50$ cells/ $\mu \mathrm{L})$ : an analysis of 338 clinical events from a randomized clinical trial. HIV Med. 2002;3(2):75-84. 
17. Taye B, Shiferaw S, Enquselassie F. The impact of malnutrition in survival of HIV infected children after initiation of antiretroviral treatment (ART). Ethiop Med J. 2010;48(1):1-10

18. Shimelash B: Assessment of the effect of malnutrition on survival of HIV infected children after initiation of antiretroviral treatment in Wolaita zone health facilities, SNNPR, Ethiopia. AAU; 2014

19. Hambisa MT, Ali A, Dessie Y. Determinants of mortality among HIV positives after initiating antiretroviral therapy in western Ethiopia: a hospital-based retrospective cohort study. ISRN AIDS. 2013;2013:491601.

20. World Health Organization: WHO child growth standards. 2006. Available at http://www.who.int/childgrowth/standards/Technical_report.pdf.

21. Turck D, Michaelsen KF, Shamir R, Braegger C, Campoy C, Colomb V, Decsi T, Domellöf M, Fewtrell M, Kolacek S. World health organization 2006 child growth standards and 2007 growth reference charts: a discussion paper by the committee on nutrition of the European society for pediatric gastroenterology, hepatology, and nutrition. J Pediatr Gastroenterol Nutr. 2013;57(2):258-64

22. Nugent J, Edmonds A, Lusiama J, Thompson D, Behets F. Predicting mortality in HIV-infected children initiating highly active antiretroviral therapy in a resource-deprived setting. Pediatr Infect Dis J. 2014; 33(11):1148-55

23. Gebremedhin A, Gebremariam S, Haile F, Weldearegawi B, Decotelli C. Predictors of mortality among HIV infected children on anti-retroviral therapy in Mekelle hospital, Northern Ethiopia: a retrospective cohort study. BMC Public Health. 2013;13:1047.

24. Njom Nlend AE, Loussikila AB. Predictors of mortality among HIV-infected children receiving highly active antiretroviral therapy. Med Mal Infect. 2016;

25. Lumbiganon P, Kariminia A, Aurpibul L, Hansudewechakul R, Puthanakit T, Kurniati N, Kumarasamy N, Chokephaibulkit K, Nik Yusoff NK, Vonthanak S, et al. Survival of HIV-infected children: a cohort study from the Asia-Pacific region. J Acquir Immune Defic Syndr. 2011;56(4):365-71.

26. Wamalwa DC, Obimbo EM, Farquhar C, Richardson BA, Mbori-Ngacha DA, Inwani I, Benki-Nugent S, John-Stewart G. Predictors of mortality in HIV-1 infected children on antiretroviral therapy in Kenya: a prospective cohort. BMC Pediatr. 2010;10:33.

27. Paton NI, Sangeetha S, Earnest A, Bellamy R. The impact of malnutrition on survival and the CD4 count response in HIV-infected patients starting antiretroviral therapy. HIV Med. 2006;7(5):323-30.

28. Zanoni BC, Phungula T, Zanoni HM, France $H$, Feeney ME. Risk factors associated with increased mortality among HIV infected children initiating antiretroviral therapy (ART) in South Africa. PLoS One. 2011; 6(7):e22706.

29. Sutcliffe CG, van Dijk JH, Munsanje B, Hamangaba F, Siniwymaanzi P, Thuma PE, Moss WJ. Risk factors for pre-treatment mortality among HIV-infected children in rural Zambia: a cohort study. PLoS One. 2011; 6(12):e29294.

30. Ebissa G, Deyessa N, Biadgilign S. Predictors of early mortality in a cohort of HIV-infected children receiving high active antiretroviral treatment in public hospitals in Ethiopia. AIDS Care. 2015;27(6):723-30.

31. Mwiru RS, Spiegelman D, Duggan C, Seage GR 3rd, Semu H, Chalamilla G, Kisenge R, Fawzi WW. Nutritional status and other baseline predictors of mortality among HIV-infected children initiating antiretroviral therapy in Tanzania. Journal of the International Association of Providers of AIDS Care. 2015;14(2):172-9.

32. Bhowmik A, Bhandari S, De R, Guha SK. Predictors of mortality among HIVinfected patients initiating anti retroviral therapy at a tertiary care hospital in eastern India. Asian Pac J Trop Med. 2012;5(12):986-90.

33. Nugent J, Edmonds A, Lusiama J, Thompson D, Behets F, Care PH, Group T. Predicting mortality in HIV-infected children initiating highly active antiretroviral therapy in a resource-deprived setting. Pediatr Infect Dis J. 2014;33(11):1148-55.

34. Shahrin L, Leung DT, Matin N, Pervez MM, Azim T, Bardhan PK, Heffelfinger JD, Chisti MJ. Characteristics and predictors of death among hospitalized HIV-infected patients in a low HIV prevalence country: Bangladesh. PLoS One. 2014;9(12):e113095.

35. Moy FS, Fahey P, Nik Yusoff NK, Razali KA, Nallusamy R. Outcomes of human immunodeficiency virus-infected children after anti-retroviral therapy in Malaysia. J Paediatr Child Health. 2015;51(2):204-8.

36. Kedir AA, Desta A, Fesseha G. Factors affecting survival of HIV positive children taking antiretroviral therapy at Adama referral hospital and medical college, Ethiopia. Journal of AIDS and Clinical Research. 2014;5(3)
37. Buck WC, Olson D, Kabue M, Ahmed S, Nchama L, Munthali A, Hosseinipour MC, Kazembe P. Risk factors for mortality in Malawian children with human immunodeficiency virus and tuberculosis co-infection. The International Journal of Tuberculosis and Lung Disease. 2013;17(11):1389-95.

38. Hailemariam S, Bune GT, Ayele HT. Malnutrition: prevalence and its associated factors in people living with HIV/AIDS, in Dilla University referral hospital. Archives of public health $=$ Archives belges de sante publique. 2013;71(1):13.

\section{Submit your next manuscript to BioMed Central and we will help you at every step:}

- We accept pre-submission inquiries

- Our selector tool helps you to find the most relevant journal

- We provide round the clock customer support

- Convenient online submission

- Thorough peer review

- Inclusion in PubMed and all major indexing services

- Maximum visibility for your research

Submit your manuscript at www.biomedcentral.com/submit

) Biomed Central 